\title{
Indian Conference on Life Cycle Management (ILCM) 2016
}

\author{
Archana Datta $^{1} \cdot$ Sakshi Bhargava ${ }^{1}$
}

Published online: 5 April 2016

(C) Springer-Verlag Berlin Heidelberg 2016

As the world is welcoming Sustainable Development Goals (SDGs) for a better future of the planet, transition towards a more sustainable economy will be requiring adoption of life cycle approaches. In line with the SDGs, the cornerstone for this year's Indian Conference on Life Cycle Management (ILCM) is the applicability of life cycle-based tools and approaches in enabling a shift towards Responsible Consumption and Production (RCP).

Encouraged by the success of past editions, the Federation of Indian Chambers of Commerce and Industry (FICCI) will be organizing the fifth edition of ILCM on 17-18 October 2016 in New Delhi, India. The conference will offer a diverse and promising program as well as workshop sessions. Participants from across the globe are welcome.

\section{Theme and focus areas}

Conference sessions will be organized around the following focus areas:
- Life Cycle Thinking to achieve Resource Efficiency

- Eco-innovation and Sustainable Products

- Proving pathways towards Circular Economy through $L C A$

- Life Cycle Inventory data as a fundamental necessity for Sustainable Production and Consumption

Contributors interested in showcasing their work are invited to submit an abstract with no more than 300 words to the conference organizers. Please refer to the guidelines for abstract submission at http://www. indialca.com/pdf/ILCM-2016-abstract-submission.pdf. The deadline for submitting abstracts is 15 July 2016. Submitted abstracts will be reviewed by the Scientific Committee of experts in the field from across the world.

For further information, browse through our conference website at http://www.indialca.com or alternatively contact the organizers at Tel: +91 (11) 23487211/+91 (11) 23487566 or via email: ilcm@ficci.com.

We are looking forward to meet you at ILCM 2016!

Archana Datta

archana.datta@ficci.com

1 Federation of Indian Chambers of Commerce and Industry, Industry's Voice for Policy Change, Federation House, Tansen Marg, New Delhi 110 001, India 